\title{
Reply to the discussion by Ganesh on "Analysis of passive earth pressure modification due to seepage flow effects"
}

Z. Hu, Department of Civil Engineering, Zhejiang University, 866 Yuhangtang Road, Hangzhou, China.

Z.X. Yang, Department of Civil Engineering, Zhejiang University, 866 Yuhangtang Road, Hangzhou, China.

S.P. Wilkinson, Department of Civil Engineering, University of Wolverhampton, Wulfruna Street, WV1 1LY, UK.

Corresponding author: Z.X. Yang (email: zxyang@zju.edu.cn).

\section{Introduction}

The authors would like to thank the Discusser (Ganesh 2018) for his interest and comments on our recent paper (Hu et al. 2018), which addressed primarily the detrimental effects of anisotropic seepage flow on passive earth pressure acting on a retaining wall, when the more realistic curved failure surface in the backfill is assumed in the calculations. The main issues raised by the Discusser include: (i) clarification of the boundary conditions; (ii) determination of the curved failure surface; (iii) applications of the proposed method. In general, we believe that the Discussion does not change the main outcomes of the original paper under Discussion, and represents further considerations/explanations alongside the paper. The authors' responses to the comments are arranged in the above order and are elaborated as follows.

\section{Clarification of the boundary conditions}

In the paper under Discussion the Authors proposed a modified approach to calculate the passive earth pressure acting on a vertical retaining wall considering anisotropic seepage effects. An analytical solution to the flow field is obtained using Fourier series expansion based on the boundary conditions illustrated in Fig. 1 in the original paper. Owning to the primary focus on the seepage flow within a backfilled layer within this paper, the horizontal surface at $y=0$ is assumed to be an impervious layer aligning with the base of the wall. In addition, the soil below the wall is assumed to be more competent than the backfill, and any curved failure is not 
allowed to breach this layer. Therefore, the boundary conditions applied in this study are in agreement with those described in Ganesh (2018), i.e. "the development of failure surface below wall toe may said to be least possible when the retaining wall simply rests on a hard stratum."

\section{Determination of the curved failure surface}

While analyzing the stability of retaining structures at the passive state, either a planar or curved failure surface is commonly adopted in the classic limit equilibrium theories (Budhu 2011). The paper under Discussion assumed a single log-spiral curve to assess the passive earth pressure coefficient $K_{\mathrm{p}}$ considering the effect of seepage flow. Such a curved failure surface was suggested by Morrison and Ebeling (1995) and then applied to the calculations of passive earth

thrust $P_{\mathrm{p}}$ in many previous studies, e.g. Soubra (2000), Škrabl and Macuh (2005) and Patki et al. (2015).

For the cases of larger values of effective internal frictionangle of the soil $\varphi^{\prime}$ and soil-wall interface friction angle $\delta$, the Discusser speculates that the curved failure surface would extend below the heel of the retaining wall. Fortunately, such scenario would not happen during passive failure following the iterative procedure presented in $\mathrm{Hu}$ et al. (2018). Through a few attempts by the iterative procedure, several curved surfaces (characterized by two angles $\theta_{v}$ and $\theta_{\mathrm{cr}}$ ) can be obtained within a prescribed tolerance, which is set as $0.1 \%$ of the mean value of $P_{\mathrm{p}}$ obtained using Eqs. (27) and (28) in the original paper. Among these results, only the failure surface with $\theta_{v} \geq \varphi^{\prime}$ and the minimum discrepancy was adopted to determine the shape of the log-spiral failure surface. Therefore the negative inclinations of failure surface near the heel of the wall can be excluded. However, such screening would not lead to severe difference of the passive earth thrust. For example, for the case of $\varphi^{\prime}=45^{\circ}, \delta=1 / 3 \varphi^{\prime}=15^{\circ}$ and the ratio of permeability coefficient $\xi=1 / 3$, the values of $K_{\mathrm{p}}$ with and without the consideration of the restriction $\theta_{v} \geq \varphi^{\prime}$ are 9.11 and 9.28 , respectively; the discrepancy is only $1.83 \%$ and is thus 
negligible as compared to the significant variations of passive earth thrust $P_{\mathrm{p}}$ induced by seepage flow inside the backfills, as shown in Fig. 8 and Table 2 in the original paper.

It is worth noting that a simplified procedure considering the planar failure surface was also presented in Hu et al. (2018), to validate and optimize the complex implementation procedure used in the curved failure surface. The analytical solution to the distribution of the effective reactive pressure $p^{\prime}$ and pore water pressure $u$ along the planar failure surface can be directly obtained by solving the Laplace equation and the modified Kötter (1903) equation. Unlike the method adopting the curved failure surface, the simplified method only requires one parameter $\varepsilon$ to determine the complete geometry of the failure surface, see Fig. 10 in the original paper. All failure surfaces would develop above the impermeable layer with the coordination $y \geq 0$.

In addition, the Discusser has raised a very interesting point on the effect of the impermeable soil layer on the passive earth pressure. The Authors agree with the Discusser's comment that, "for such cases, the interface friction angle between the hard stratum and backfill would be expected to play a crucial role on the magnitude of passive earth pressure which cannot be simply omitted in the design of retaining structures." There is no doubt that such friction would generate more complicated failure surfaces, e.g. a log-spiral failure surface with $\theta_{v} \geq \varphi^{\prime}$ at the heel of the wall, or a planarfailure surface along the impermeable layer near the wall heel combining with a curved failure surface extending to the backfill surface. The authors believe this would deserve further investigation focusing on the shape of failure surface and evolution of earth pressure, utilizing numerical analyses alongside laboratory experiments, which are beyond the scope of the paper under Discussion. 


\section{Applications of the proposed method}

With respect to the potential application of the proposed method, the Discusser stated that, "the seepage analysis carried out is based on oversimplifying assumptions that rarely follow or occur in problems dealing with passive earth pressure." However, this is the case for all theoretical models. Even the Laplace equation assumes laminar seepage flow inside the backfill and that the flow obeys the linear Darcy's law. In fact, during heavy rainfall, the pore water pressure inside the backfill will increase with the development of water infiltration, leading to the reduction of soil strength and instability of retaining structures. Under such conditions, a drainage system is normally applied along the soil-wall interface to reduce the pore water pressure behind the wall. Fig. R1 shows the distribution of the normalized pressure head $h_{\mathrm{p}} / H$ inside the backfill, indicating a lower pore water pressure near the soil-wall interface compared to that of a hydrostatic condition without seepage flow. Due to the advantages and extensive application of the drainage system along the retaining wall, it is of great importance in assessing the effect of seepage flow under such boundary conditions.

To obtain the distribution of pore water pressure inside the backfill and the reactive force along the curved failure surface, several assumptions have been elaborated in the paper under Discussion. Note that these assumptions have also been adopted for the analysis of passive earth pressure acting on retaining wall, e.g. Morrison and Ebeling (1995), Soubra and Macuh (2002), and Patki et al. (2015). Particularly, the same boundary conditions of seepage flow inside the backfill were also adopted in Barros (2006), Wang et al. (2008), Santos and Barros (2015) and Hu et al. (2017). The distribution of the normalized pressure head $h_{\mathrm{p}} / H$ along a logspiral failure surface is illustrated in Fig. R2.

Note that for the case with the lower impermeable layer, upward seepage flow may occur around the heel of the wall, which could lead to liquefaction, heave, piping, or bearing capacity failure before the passive sliding failure. Therefore, the impermeable layer at $y=0$ was adopted 
instead of the lower impermeable layer. Bearing all of these considerations in mind, the boundaryconditions applied in Hu et al. (2018) are valid and applicable in engineering practice.

\section{Acknowledgements}

The research described in this paper was supported by the National Key Basic Research Program of China (No. 2015CB057801), the National Key R \& D program of China (No. 2016YFC0800200), and Natural Science Foundation of China (Nos. 51578499 and 51761130078), which are gratefully acknowledged. 


\section{References}

Barros, P.L.A. 2006. A Coulomb-type solution for active earth thrust with seepage. Géotechnique, 56(3): 159-164.

Budhu, M. 2011. Soil mechanics and foundations. John Wiley \& Sons, New York.

Ganesh, R. 2018. Discussion of "Analysis of passive earth pressure modification due to seepage flow effects". Canadian Geotechnical Journal.

Hu, Z., Yang, Z.X., and Wilkinson, S.P. 2017. Active earth pressure acting on retaining wall considering anisotropic seepage effect. Journal of Mountain Science. 14(6): 1202-1211.

Hu, Z., Yang, Z.X., and Wilkinson, S.P. 2018. Analysis of passive earth pressure modification due to seepage flow effects. Canadian Geotechnical Journal, 55(5): 666-679.

Kötter, F. 1903. Die bestimmung des Druckes an gekrummten Gleitflachen, eine Aufgabe aus der Lehre Vom Ediddruck. Sitzungsberichteder Akademie der Wissenschaften, Berlin.

Morrison, E.E., Jr., and Ebeling, R.M. 1995. Limit equilibrium computation of dynamic passive earth pressure. Canadian Geotechnical Journal, 32(3): 481-487.

Patki, M.A., Mandal, J.N., and Dewaikar, D.M. 2015. A simple approach based on the limit equilibrium method for evaluating passive earth pressure coefficients. Geotechnik, 38(2): 120-133.

Santos, P.J., and Barros, P.L.A. 2015. Active earth pressure due to soil mass partially subjected to water seepage. Canadian Geotechnical Journal, 52(11): 1886-1891.

Škrabl, S., and Macuh, B. 2005. Upper-bound solutions of three-dimensional passive earth pressures. Canadian Geotechnical Journal, 42(5): 1449-1460.

Soubra, A.-H. 2000. Static and seismic passive earth pressure coefficients on rigid retaining structures. Canadian Geotechnical Journal, 37(2): 463-478.

Soubra, A.-H., and Macuh, B. 2002. Active and passive earth pressure coefficients by a kinematical approach. Proceedings of the Institution of Civil Engineers-Geotechnical Engineering, 155(2): 119-131. 
Wang, J.J., Liu, F.C., and Ji, C.L. 2008. Influence of drainage condition on Coulomb-type active earth pressure. Soil Mechanics and Foundation Engineering, 45: 161-167.

\section{Figure Captions}

Fig. R1 Distribution of the normalized pressure head inside the backfill

Fig. R2 Distribution of the normalized pressure head along the failure surface

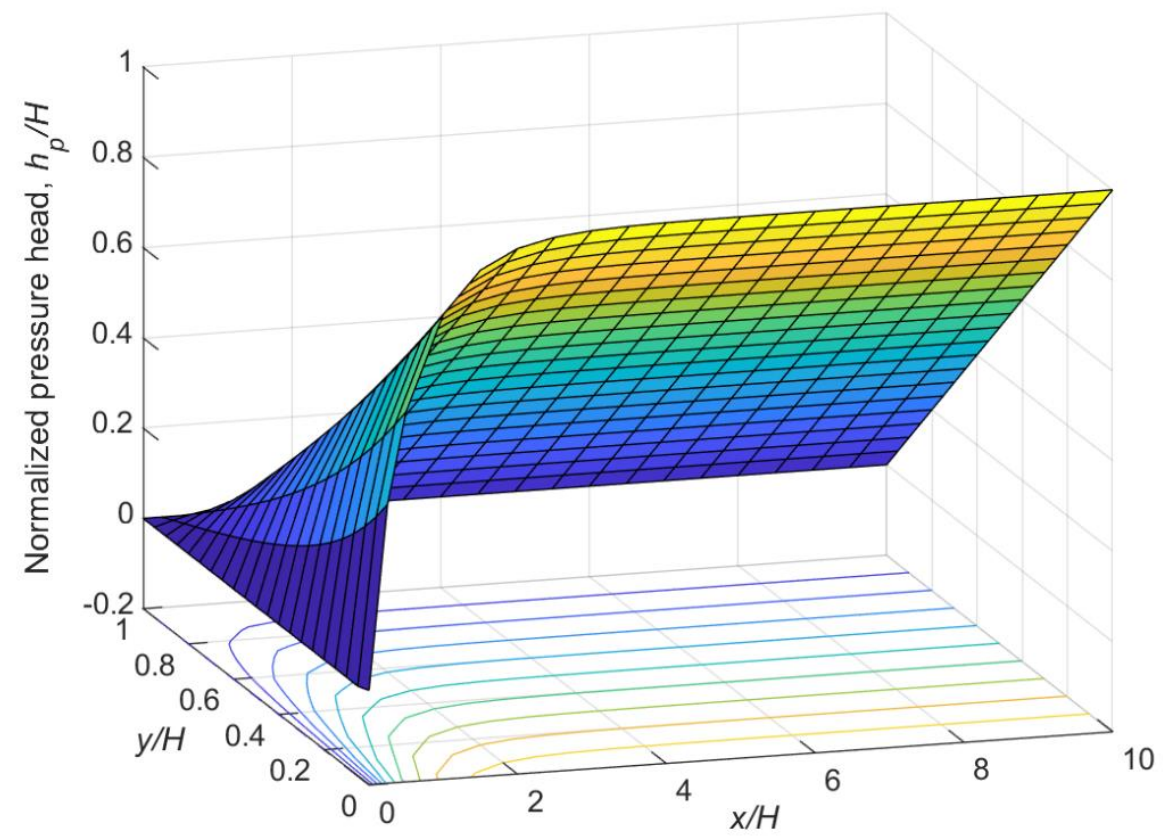

Fig. R1 Distribution of the normalized pressure head inside the backfill 


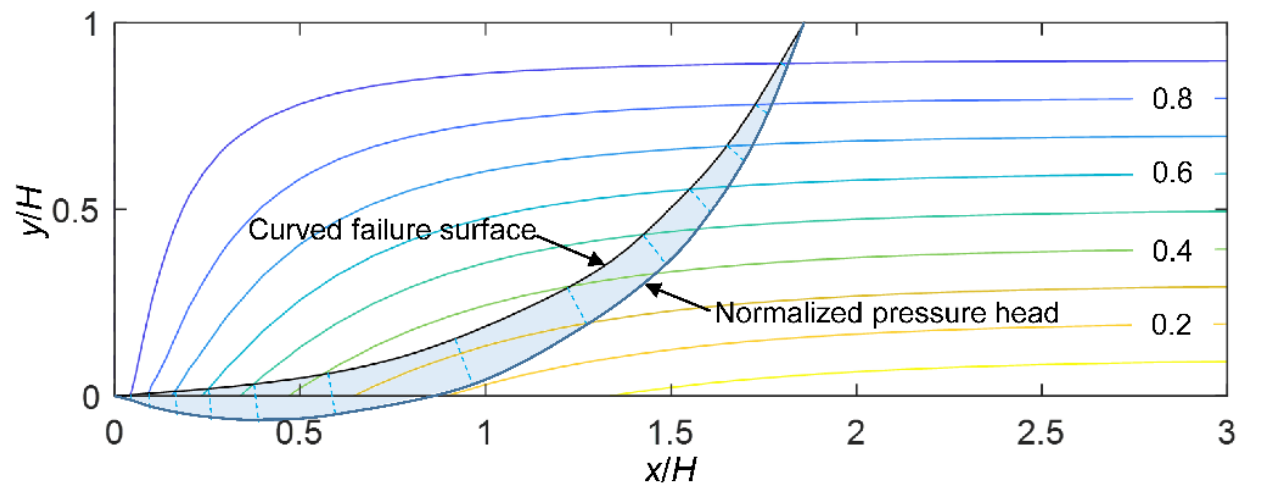

Fig. R2 Distribution of the normalized pressure head along the failure surface 